\title{
Recidiva de Lesões Associadas ao HPV em Pacientes HIV Positivos Após Tratamento Cirúrgico
}

\section{Recurrence of HPV Lesions after Surgical Treatment in HIV-Positive Patients}

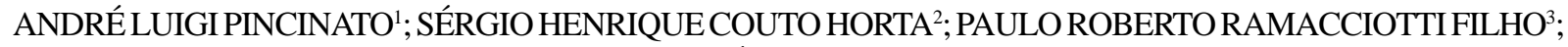 \\ GALDINO JOSÉ SITONIO FORMIGA';
}

\author{
1. Assistente do Serviço de Coloproctologia do Hospital Heliópolis - São Paulo, SP; ${ }^{2}$ Assistente do \\ Serviço de Coloproctologia do Hospital Heliópolis - São Paulo, SP; ${ }^{3}$ Residente do Serviço de \\ Coloproctologia do Hospital Heliópolis - São Paulo, SP; ${ }^{4}$ Chefe do Serviço de Coloproctologia do Hospital \\ Heliópolis - São Paulo, SP.
}

PINCINATO AL; HORTA SHC; RAMACCIOTTI FILHO PR, FORMIGA GJS. Recidiva de Lesões Associadas ao HPV em Pacientes HIV Positivos após Tratamento Cirúrgico. Rev bras Coloproct, 2009;29(2): 169-173.

RESUMO: O HPV é a doença anal sexualmente transmissível mais diagnosticada em pacientes HIV positivos. Neste estudo investigamos a taxa de recidiva após tratamento cirúrgico do HPV em pacientes HIV positivos. Foi realizado um estudo retrospectivo em 74 pacientes que foram submetidos a tratamento cirúrgico de lesões remanescentes após tratamento clínico do HPV, no Hospital Heliópolis, São Paulo, Brasil, de julho de 2004 até junho de 2007. A maioria dos pacientes eram homens (91,9\%), idade variando de 22 a 57 anos (média de 36 anos). Carga viral variou de indetectável até 488.000 cópias/mm², células T CD4 de 19 a 900 céls $/ \mathrm{mm}^{3}$. Observamos neoplasia intraepitelial de alto grau em 12,2\% e recorrência das lesões em 58,1\% dos pacientes. A recorrência foi significantemente menor em pacientes com células $\mathrm{T}$ CD4 $=200 \mathrm{cells} / \mathrm{mm}^{3}$ e carga viral indetectável.

Descritores: HPV anal, Condiloma anal, AIDS, Recidiva, Displasia anal.

\section{INTRODUÇÃO}

O Papilomavírus humano (HPV) se destaca como uma das doenças sexualmente transmissíveis (DST) de maior incidência e prevalência no mundo. ${ }^{1}$ Dentre indivíduos com Vírus da Imunodeficiência $\mathrm{Hu}-$ mana (HIV) este é o agente etiológico mais frequente de doenças da região anal. ${ }^{2-4}$ Sua incidência vêm aumentando desde o início da epidemia da Síndrome de Imunodeficiência Adquirida (AIDS), sugerindo que a imunodepressão é um importante fator no aparecimento do condiloma. ${ }^{2-4}$

A transmissão é comumente por relação sexual, e é estimado que mais de $50 \%$ das pessoas sexualmente ativas tenham sido infectadas por HPV em algum momento de suas vidas. ${ }^{5} \mathrm{O}$ acometimento anal é comum e predomina em grupos com comportamento de risco para DST, antecedentes de tratamento de HPV genital ou anal prévio e portadores de prurido anal idiopático. ${ }^{1,6-9} \mathrm{O}$ HPV também pode ser transmitido por via oral, manual ou vestimentas, pela proximidade com os genitais. ${ }^{6,10,11}$

A maioria das infecções por HPV são assintomáticas, sendo que apenas $10 \%$ dos pacientes desenvolverão lesões verrucosas ou displasias. ${ }^{3,12,13} \mathrm{Em}$ pacientes HIV positivos, as manifestações anogenitais são mais agressivas e com maior número de recidivas.,10,12-14

O grau de imunidade dos pacientes, o vírus HIV e a agressividade viral estão relacionados a maiores taxas de prevalência, severidade, persistência e recidiva no tratamento do HPV. ${ }^{15,16}$

O objetivo desse estudo é avaliar a recidiva de lesões associadas ao HPV anal em pacientes HIV positivos após tratamento cirúrgico.

$\overline{\text { Trabalho realiza }}$ do no Serviço de Coloproctologia do Hospital Heliópolis, São Paulo, SP - Brasil. 


\section{MÉTODO}

Realizamos levantamento retrospectivo dos casos de lesões condilomatosas anais em pacientes HIV positivos tratados cirurgicamente no Hospital Heliópolis, no período de julho de 2004 a junho de 2007.

O diagnóstico foi feito através da inspeção da região perianal e toda área genital, seguido do exame de anuscopia e feito biópsia para confirmação diagnóstica.

Eram feitas aplicações semanais de podofilina a $25 \%$ nos condilomas localizados na margem anal e de ATA 95\% acima da linha pectínea, inclusive em lesões volumosas. As remanescentes após a quarta aplicação eram tratadas com exérese e/ou cauterização. $\mathrm{O}$ tecido retirado foi enviado para exame histológico para confirmação histopatológica e avaliação da presença de atipias. O seguimento foi mensal até o sexto mês. Em caso de recidiva, retornava-se ao protocolo inicial. Foram excluídos do trabalho os pacientes que perderam acompanhamento nos primeiros meses de seguimento.

As variáveis avaliadas foram sexo, idade, localização das lesões, níveis de linfócitos T CD4 e carga viral, diagnóstico histopatológico e presença de recidiva. Para a análise estatística foi utilizado o programa SPSS 12.0, teste $t$ de Student para variáveis quantitativas e teste do qui-quadrado para variáveis nominais, sendo considerado significante $\mathrm{p}<0,05$.

\section{RESULTADOS}

Foram incluídos no trabalho 74 pacientes com idade variando de 22 a 57 anos, média de 36 anos. $\mathrm{O}$ grupo estudado era composto principalmente por homens $(91,9 \%)$ na faixa etária de 31 a 40 anos $(44,6 \%)$ geralmente acometendo tanto a margem quanto o canal anal $(79,7 \%)$. O resultado anátomo-patológico revelou neoplasia intraepitelial (NIA) de alto grau em nove casos $(12,2 \%)$. As características da amostra quanto a sexo, idade, localização das lesões e diagnóstico histopatológico estão descritas no quadro 1.

A variação da contagem de linfócitos T CD4+ variou de 19 a 900 células/mm3 e a carga viral para HIV de indetectável até 488.000 cópias $/ \mathrm{mm} 3$. A recidiva ocorreu em 43 pacientes $(58,1 \%)$. Vinte e dois pacientes $(29,7 \%)$ tinham níveis de CD4 < 200 cél/ $\mathrm{mm}^{3}$ e $95,5 \%$ destes recidivaram, enquanto entre os
$52(70,3 \%)$ com CD4 = 200 cél $/ \mathrm{mm}^{3}$, apenas 42,3\% recidivaram.

Foi observada uma associação significativa na distribuição das frequências de recidiva de acordo com o valor de corte para CD4 em 200 células $/ \mathrm{mm}^{3}$, com o grupo com CD4 $<200$ células $/ \mathrm{mm}^{3}$ apresentando recidivas mais frequentes. $\left(x^{2}=17,938, p<0,001\right)$ (Tabela $1)$.

Dos 32 pacientes $(43,2 \%)$ com carga viral indetectável, nove $(28,1 \%)$ recidivaram, enquanto 42 pacientes $(56,8 \%)$ com carga viral detectável, 34 recidivaram $(81 \%)$.

Portanto, os pacientes que apresentavam carga viral detectável tiveram maiores índices de recidiva. $\left(x^{2}=20,822, p<0,001\right)$ (Tabela 2$)$.

\section{DISCUSSÃO}

A prevalência da infecção por HPV na região anorretal está estimada em 4,68\% em nosso meio. ${ }^{1} \mathrm{~A}$ infecção anal pelo HPV em pacientes HIV positivos ocorre principalmente em pacientes homossexuais masculinos na faixa etária de 30 a 40 anos. ${ }^{5,17,18}$ Entre pacientes homossexuais masculinos soronegativos, o HPV anal está presente em $61 \%$ dos casos, mas acomete $93 \%$ dos soropositivos. ${ }^{19}$ Entre as mulheres, esses valores correspondem a $42 \%$ e $76 \%$, respectivamente. $^{20}$

Quadro 1 - Características clínico-patológicas da amostra.

\begin{tabular}{lrr}
\hline Característica & Pacientes & \% \\
\hline Sexo & & \\
masculino & 68 & 91,9 \\
feminino & 6 & 8,1 \\
Faixa etária & & \\
$21-30$ & 24 & 32,4 \\
$31-40$ & 33 & 44,6 \\
$41-50$ & 12 & 16,2 \\
$51-60$ & 5 & 6,8 \\
Localização das lesões & & \\
Canal anal & 11 & 14,9 \\
Margem anal & 4 & 5,4 \\
Canal e margem anal & 59 & 79,7 \\
Diagnóstico histopatológico & & \\
NIA de alto grau & 9 & 12,2 \\
\hline
\end{tabular}


Tabela 1 - Distribuição das frequências de recidiva de HPV, de acordo com a contagem de linfócitos CD4+, tendo valor de corte 200 células $/ \mathrm{mm}^{3}$.

\begin{tabular}{|c|c|c|c|}
\hline \multirow[t]{2}{*}{ Contagem de células T CD4+ } & \multicolumn{2}{|c|}{ Recidiva HPV } & \multirow[t]{2}{*}{ Total } \\
\hline & Sim N (\%) & Não N (\%) & \\
\hline$<200 \mathrm{cel} / \mathrm{mm}^{3}$ & $21(95,5)$ & $1 \quad(4,5)$ & 22 \\
\hline$=200 \mathrm{cel} / \mathrm{mm}^{3}$ & $22(42,3)$ & $30(57,7)$ & 52 \\
\hline Total & $43(58,1)$ & $31(41,9)$ & 74 \\
\hline
\end{tabular}

$x 2=17,938 \quad p<0,001$.

Tabela 2 - Distribuição das frequências de recidiva de HPV, de acordo com a detecção da carga viral para HIV.

\begin{tabular}{lccc}
\hline Carga Viral para HIV & \multicolumn{2}{c}{ Recidiva HPV } & Total \\
\cline { 2 - 3 } & Sim N (\%) & Não N (\%) & 32 \\
\hline Indetectável & $9(28,1)$ & $23(71,9)$ & 42 \\
Detectável & $34(81,0)$ & $8(19,0)$ & 74 \\
Total & $43(58,1)$ & $31(41,9)$ & \\
\hline
\end{tabular}

$x 2=20,822 \quad p<0,001$.

$\mathrm{O}$ acometimento do canal e margem anal concomitante foi maior do que o acometimento isolado de cada uma dessas localizações, corroborando dados da literatura. ${ }^{13,17}$ A presença de lesão acima da linha pectínea, ocorreu em $85,1 \%$ dos casos em nosso estudo. Segundo a literatura este é um fator associado a maior incidência de displasias anais. $^{21}$

O diagnóstico histopatológico de neoplasia intraepitelial de alto grau foi feito em $12,2 \%$ dos casos operados, semelhantes aos dados da literatura que mostram índices de $16,4-23,1 \%$. $^{3,13,19}$ Além da soropositividade para o HIV, a imunodeficiência, a contagem de linfócios CD4 menor que $500 / \mathrm{mm}^{3}$, o tipo do HPV (principalmente 16 e 18), as lesões acima da linha denteada e o intercurso sexual anal estão associados a aumento da probabilidade de displasia anal relacionada ao HPV. ${ }^{9,13,19-21}$

A recidiva dos condilomas acuminados anais ocorre entre $4 \%$ e $84 \%$ dos doentes independentemente do tipo de tratamento realizado, não havendo um tratamento mais indicado para pacientes com HIV e verrugas anais. ${ }^{22-24}$

Optamos por adotar o tratamento proposto por Nadal e $\mathrm{col}^{12}$, onde inicialmente é realizado o tratamento tópico o que proporciona a redução no tamanho dos condilomas, tornando a ressecção cirúrgica mais fácil ${ }^{12,15}$. Além disso, a utilização de medicação tópica prévia pode prolongar o período sem recidivas. ${ }^{13}$ Após esse tratamento, nossa taxa de recidiva foi de $58,1 \%$, semelhante aos dados da literatura. ${ }^{12,13,16-18}$

A recidiva do condiloma em pacientes HIV positivos após tratamento é frequente. Apesar da terapia apropriada poder proporcionar períodos livres de sintomas para pacientes soropositivos, não há evidencias de que o tratamento elimine a infecção pelo HPV da região anorretal. Isso ocorre devido ao contato sexual repetido, localização do vírus longe dos linfáticos, lesões profundas ou esquecidas, forma latente do vírus, período de incubação longo do HPV e por alteração da imunidade local. ${ }^{12,18}$

A recidiva foi maior no grupo que apresentava contagem de linfócitos T CD4 $<200 \mathrm{cel} / \mathrm{mm}^{3}$ e carga viral detectável, demonstrando que a imunodepressão é um fator importante para a recidiva. Em seu estudo sobre HPV em pacientes imunodeprimidos, de la Fuente e $\mathrm{col}^{18}$ também observaram maior recidiva em pacientes com contagem de CD $4<200 \mathrm{cel} / \mathrm{mm}^{3}$, sen- 
Recidiva de Lesões Associadas ao HPV em Pacientes

HIV Positivos após Tratamento Cirúrgico

André Luigi Pincinato e Cols.
Vol. 29 $\mathbf{N}^{\circ} 2$ do que nenhuma recidiva estava relacionada a contagens de CD4 maiores que $400 \mathrm{cel} / \mathrm{mm}^{3}$. Este estudo não mostrou associação entre a carga viral e a recidiva. ${ }^{18}$ No entanto, nosso estudo demonstrou que pacientes HIV positivos com carga viral detectável, apresentam maiores índices de recidiva após tratamento cirúrgico.

\section{CONCLUSÃO}

A recidiva das lesões de HPV anal, em pacientes HIV positivos é elevada mesmo em pacientes submetidos a tratamento cirúrgico, sendo maior naqueles com taxas de linfócitos T CD4+ < 200 células $/ \mathrm{mm}^{3}$ e carga viral detectável.

\begin{abstract}
HPV is the commonest anal disease in HIV-infected patients. In the present study we investigated the recurrence rates after surgical treatment of HPV in HIV-positive patients. A retrospective review was performed on 74 patients who underwent surgical intervention for medically intractable anal condyloma at Hospital Heliópolis, São Paulo, Brazil, from July 2004 to June 2007. The majority of the patients were male $(91,9 \%)$, ranged in age from 22 to 57 years (mean 36 years). Viral load ranged from undetectable to 488.000 copies $/ \mathrm{mm}^{3}$, T CD4 cells counts from 19 to 900 cells $/ \mathrm{mm}^{3}$. We observed high grade anal squamous intraepithelial lesions in $\mathbf{1 2 , 2 \%}$ and anal condyloma recurred in $\mathbf{5 8 , 1 \%}$. A significantly lower recurrence was observed in patients with $\mathrm{T}$ CD4 cells counts $=200$ cells $/ \mathrm{mm}^{3}$ and viral load undetectable.
\end{abstract}

Key words: Anal HPV, Anal wart, AIDS, Recurrence, Anal dysplasia.

\section{REFERÊNCIAS}

1. Magi JC, Brito EMS, Grecco ETO, Pereira SMM, Formiga, GJS. Prevalência de Papilomavirus humano (HPV) anal, genital e oral, em ambulatório geral de coloproctologia. Rev bras Coloproct 2006; 26(3): 233-238.

2. Nadal SR, Calore EE, Nadal LRM, Horta SHC, Manzione CR. Citologia anal para rastreamento de lesões pré-neoplásicas. Rev. Assoc. Med. Bras 2007; 53(2): 147-151.

3. Manzione CR, Nadal SR, Calore EE. Oncogenicidade do Papilomavirus humano e o grau de neoplasia intra-epitelial anal em doentes HIV positivo. Rev. Assoc. Med. Brás 2004; 50(3): 282-285.

4. Calore EE, Manzione CR, Nadal SR, Cavalieri MJ, Calore NMP, Santos RP. Ki-67 expression in anal intraepithelial neoplasia in AIDS. São Paulo Med. J 2001; 119(3): 119-121.

5. Manhart LE, Koutsky LA. Do Condoms Prevent Genital HPV infection, External Genital Warts, or Cervical Neoplasia? A Meta-Analysis. Sex Transm Dis 2002; 29(11): 725-735.

6. Birley HDL. Continuing medical ignorance: modern myths in the management of genital warts. Int J STD AIDS 2001; 12(2): 71-74.

7. Cañadas MP, Bosch FX, Junquera ML, Ejarque M, Font R, Ordoñez E, Sanjosé S. Concordance of prevalence of human Papillomavirus DNA in anogenital and oral infections in a high-risk population. J Clin Microbiol 2004; 42(3): 13301332.

8. Soto Y, Mune M, Morales E, Goicolea A, Mora J, Sanches L, Ramirez R, Alfonso M, Kouri V, Hengge UR. Human Papillomavirus Infections in Cuban Women With Cervical
Intraepithelial Neoplasia. Sex Transm Dis 2007; 34(12): 974976.

9. Hagensee ME, Cameron JE, Leigh JE, Clark RA. Human papillomavirus infection and disease in HIV-infected individuals. Am J Med Sci 2004; 328(1): 57-63.

10. Abramowitz L, Benabderrahmane D, Ravaud P, Walker F, Rioux C, Jestin C, Bouvet E, Soulé JC, Leport C, Duval X. Anal squamous intraepithelial lesions and condyloma in HIVinfected heterosexual men, homosexual men and women: prevalence and associated factors. AIDS 2007; 21(11): 14571465.

11. Magi JC, Rodrigues MRS, Moreno WD, Fraga, JBP, Costa ACL, Formiga GJS. A importância da anuscopia de alta resolução para o diagnóstico do Papilomavirus humano anorretal na forma subclínica, das lesões anais intraepiteliais e do carcinoma "in situ" anal. Rev Col Bras Cir 2004; 31(1): 39-45.

12. Nadal SR, Manzione CR, Horta SHC, Calore EE - Sistematização do atendimento dos portadores de infecção perianal pelo Papilomavirus humano (HPV). Rev bras Coloproct 2004; 24(4): 322-328.

13. Manzione CR, Nadal SR, Calore EE. Postoperative followup of anal condylomata acuminata in HIV-positive patients. Dis Colon Rectum 2003; 46(10): 1358-1365.

14. Kojic EM, Cu-Uvin S. Update: human papillomavirus infection remains highly prevalent and persistent among HIVinfected individuals. Curr Opin Oncol 2007; 19(5): 464-469.

15. Nadal SR, Manzione CR. Doente portador de condiloma acuminado perianal recidivante: o que fazer? Rev Assoc Med Bras 2001; 47(4): 278-279.

16. De Panfilis G, Melzani G, Mori G, Ghidini A, Graifemberghi 
S. Relapses after treatment of external genital warts are more frequent in HIV-positive patients than in HIV-negative controls. Sex Transm Dis 2002; 29(3): 121-125.

17. Nadal SR, Manzione CR, Galvão VM, Salim VRB, Speranzini MB. Perianal diseases in HIV-positive patients compared with a soronegative population. Dis Colon Rectum 1999; 42: 649654.

18. de la Fuente SG, Ludwig KA, Mantyh CR. Preoperative immune status determines anal condyloma recurrence after surgical excision. Dis Colon Rectum 2003;46: 367-372.

19. Palefsky JM, Holly EA, Ralson ML, Jay N. Prevalence and risk factors for Human Papillomavirus infection of the anal canal in Human Immunodeficiency Virus (HIV)-positive and HIV-negative homosexual men. JID 1998; 177: 361-367.

20. Palefsky JM, Holly EA, Ralson ML, Da Costa M, Greenblatt RM. Prevalence and risk factors for Human Papillomavirus infection of the anal canal in Human Immunodeficiency Virus (HIV)-positive and high-risk HIV-negative women. JID 2001; 183: 383-391.
21. Chang GJ, Berry JM, Jay N, Palefsky JM, Welton ML. Surgical treatment of high-grade anal squamous intraepithelial lesions: a prospective study. Dis Colon Rectum 2002; 45(4): 453-458.

22. Metcalf AM, Dean T. Risk of dysplasia in anal condiloma. Surgery 1995; 118: 724-726.

23. Abbasakoor F, Boulos PB. Anal intraepithelial neoplasia. Br J Surg 2005; 92(3): 277-290.

24. Beck DE, Jaso RG, Zajac RA. Surgical management or anal condyloma in the HIV-positive patient. Dis Colon Rectum 1990; 33: 180-183.

\section{Endereço para correspondência:}

GALDINO JOSÉ SITONIO FORMIGA

Serviço de Coloproctologia do Hospital Heliópolis R. Cônego Xavier, 276- Vila Nova Heliópolis 04231-030- São Paulo, SP

T.: 11- 2274-7600 (ramal 244)

Fax: 11-2247-7646

E-mail: gformiga@ig.com.br 